Sharif University of Technology
Scientia Iranica
SCIENTIA
IRANICA

\title{
Applying a multi-sensor system to predict and simulate the tool wear using artificial neural networks
}

\author{
A. Salimiasl ${ }^{\mathrm{a}, *}$, A. Erdem ${ }^{\mathrm{b}}$ and M. Rafighic \\ a. Department of Mechanical Engineering, Payame Noor University, Tehran, Iran. \\ b. Department of Computer Engineering, Faculty of Technology, University of Gazi, Ankara, Turkey. \\ c. Department of Manufacturing Engineering, Faculty of Technology, University of Gazi, Ankara, Turkey.
}

Received 19 September 2015; received in revised form 24 October 2016; accepted 8 November 2016

\section{KEYWORDS}

Tool flank wear; Cutting forces;

ANN;

Vibration amplitude.

\begin{abstract}
Cutting tool wear in machining processes reduces the product surface quality, affects the dimensional and geometrical tolerances, and causes tool breakage during the metal cutting. Therefore, online tool wear monitoring is needed to prevent reduction in machining quality. An Artificial Neural Network (ANN) model was developed in this study to predict and simulate the tool flank wear. To achieve this aim, an experiment array was provided using full factorial method, and the tests were conducted on a CNC lathe machine tool. Vibration amplitude of the cutting tool and cutting forces were considered as criterion variables in monitoring the tool flank wear. For designing the model, the cutting parameters, cutting forces, and vibration amplitude were defined as model inputs, and tool flank wear was selected as an output. The model was also introduced as a simulation block diagram to be used as a useful model in online and automated manufacturing systems. The estimated and measured results were then compared with each other. Based on the comparison results, maximum squared error values are under $6 \times 10^{-14} \mathrm{~mm}$, and $R^{2}$ is 1 , meaning that the designed model can predict the results with high and reliable accuracy.

(C) 2017 Sharif University of Technology. All rights reserved.
\end{abstract}

\section{Introduction}

Nowadays, Tool Condition Monitoring systems (TCM) are essential to establish unmanned and automated manufacturing systems. However, tool monitoring is a difficult task due to the nonlinear system of most machining processes [1]. Monitoring the cutting tool wear during the machining is one of the important phases of the tool condition monitoring. Cutting tool wear failures increase machining operation time by $20 \%$. Tool wear directly affects surface roughness,

*. Corresponding author. Tel.: +984135412306 E-mail addresses: aydin952@gmail.com (A. Salimiasl); ayerdem@gazi.edu.tr (A. Erdem); m.rafighi@gazi.edu.tr (M. Rafighi)

doi: $10.24200 /$ sci. 2017.4247 dimensional precision, and cost of the final product. Also, cutting tool wear causes sudden tool breakages, resulting in a costly machine tool damage.

Two methods are available for tool wear measurement: direct and indirect methods. In the direct method, tool wear can be obtained directly. For instance, Kurada and Bradley [2] applied direct method using laser to acquire tool wearing. In indirect methods of wear estimation, the obtained signals are applied into signal features, used to predict the values of wear by a suitable wear model. Scheffer and Heyns [3] and Balazinski et al. [4] reported that most TCM systems employ forces and only a few systems utilize vibration signal as input parameters. Combinations of both force and vibration signals are more appropriate to improve the performance of prediction models. Various methods have been used by researchers to estimate and predict the tool wear during machining process. Zhou, 
Kasashima, and some other researchers used a new method that makes use of wavelet techniques to monitor the cutting process and estimate tool failure in face milling operation [5]. Bhattacharyya and Sengupta used an OLTCM method based on time features And Multiple Linear Regression (MLR) models by using force signal to introduce a statistical model [6]. These studies have gained different degrees of success in tool wear prediction; however, using modern methods to recognize the tool wear will increase the performance of the developed models. Among the modern methods, Artificial Neural Networks (ANN) are a robust tool in the prediction and estimation of the nonlinear incidents such as tool wear in machining. Also, ANN has a lot of other important applications in various fields of engineering sciences. Many review studies were reported with applications of ANN in the field of drying processes for forecasting, atmospheric sciences, sizing of solar photovoltaic systems, and modeling of energy systems, such as modeling of heat exchangers, estimation of heat exchanger parameters, etc. [7,8].

In the field of machining, ANN method has been used by various researchers to model the cutting processes in recent years. Bukkapatnam et al. [9] developed an ANN for predicting the tool flank wear. In this model, the extracted features are given to the ANN model and the flank wear is estimated. J.T. Lin et al. [10] used the regression analysis and ANN method for monitoring the tool wear. İbrahim et al. [11] developed a new method for monitoring the tool wear using ANN method.

Cutting force is one of the best variables which reflects the condition of the cutting process during the machining $[12,13]$. Therefore, the procedure of the cutting force monitoring has received attention of many researchers to detect the tool condition, work piece accuracy, etc. [14-21]. Many studies have been conducted to implement an effective tool to prevent the tool breakage by monitoring the cutting force [22].

Vibration sensing methods are one of the other important approaches which have been tried for tool wear monitoring and estimation by various researchers in recent years [23-25]. The vibration types generated during the machining operation are divided into vibrations which are:

(i) Dependent on the cutting process and tool wear;

(ii) Independent of the cutting process and tool wear.

Since the tool wear is a result of the cutting operation, vibrations during the machining operation must be monitored and saved to generate the vibration and tool wear relationships. Tool wear happening causes an increase in cutting tool vibration amplitudes which can be used as a criterion for tool condition wear and tool life [23].
The goal of this study is to establish a robust tool wear estimation model for improving the extenuation of the past studies. So, by applying the cutting force and vibration amplitude values, the tool flank wear is predicted in turning operation. MATLAB program was applied for designing the prediction model. Artificial neural network model was utilized for the prediction of flank wear in this system. In the ANN model, cutting parameters, vibration and cutting forces were regarded as the inputs, and the wear rate was considered as the output parameters. Signals were obtained directly from the sensor by the experimental data. Then, wear rate is predictable from the obtained result of ANN method. To enhance the performance of the method in relation to the other studies, the model was simulated to be applicable to machine tools, adaptive control, and automated systems. Therefore, the created simulation block diagram can be easily used with machine tool feed and spindle drive block diagrams to establish an adaptive cutting force control system. Also, the introduced method in this study is more practical and easy for small machining plants without any need for any extra mathematical modeling. Moreover, based on the obtained error values, the results of the developed model in this study are more accurate and reliable.

\section{Experimental work and procedure}

In this study, in addition to cutting forces, vibration amplitude was measured to estimate the amount of wear. Two variables to estimate wear were used to ensure the reliability of the estimation and monitoring processes. The experiments were designed using full factorial method (Table 1). A turning CNC machine tool (Johnford TC-35 CNC) was used for conducting the experiments. A Sandvik-Coromant insert (TNMG 1604-QM H13) was selected as the cutting tool along with a TIZIT Simple (CTANR 2525M16) tool holder. The insert geometries are given in Figure 1 and Table 2. The material used for machining was SAE 4140 with $\varnothing 100 \times 1000 \mathrm{~mm}$ of dimension. Chemical properties of the work piece are given in Table 1 . Chemical composition and mechanical properties of the mate-

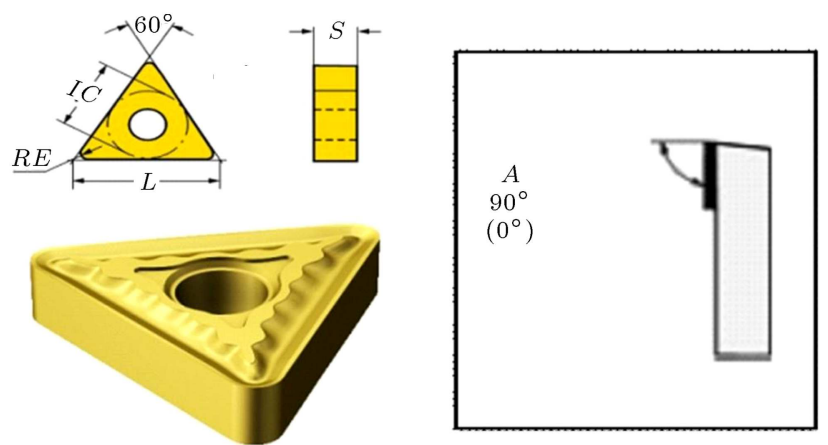

Figure 1. Geometry of the insert and tool holder. 
Table 1. The used experiment array.

\begin{tabular}{|c|c|c|c|c|c|c|c|c|c|c|c|c|c|c|c|}
\hline$N$ & $\boldsymbol{V}$ & $f$ & $d$ & $a$ & $\boldsymbol{F}$ & $V_{b}$ & $\begin{array}{c}V_{b} \\
\text { (model) }\end{array}$ & $N$ & $V$ & $f$ & $d$ & $a$ & $F$ & $V_{b}$ & $\begin{array}{c}V_{b} \\
\text { (model) }\end{array}$ \\
\hline 1 & 110 & 0.22 & 0.75 & 1.89 & 526.183287 & 0 & 0.0069 & 55 & 135 & 0.17 & 1.25 & 2.21 & 795.3483514 & 0.2 & 0.196 \\
\hline 2 & 110 & 0.22 & 0.75 & 2.18 & 547.6474923 & 0.1 & 0.105 & 56 & 135 & 0.17 & 1.25 & 2.41 & 841.8509369 & 0.3 & 0.297 \\
\hline 3 & 110 & 0.22 & 0.75 & 2.36 & 594.0177922 & 0.2 & 0.197 & 57 & 160 & 0.17 & 1.25 & 1.92 & 616.4862577 & 0 & 0.0074 \\
\hline 4 & 110 & 0.22 & 0.75 & 2.52 & 639.1632557 & 0.3 & 0.298 & 58 & 160 & 0.17 & 1.25 & 2.11 & 681.8696716 & 0.1 & 0.101 \\
\hline 5 & 135 & 0.22 & 0.75 & 1.91 & 476.5769542 & 0 & 0.0069 & 59 & 160 & 0.17 & 1.25 & 2.33 & 792.0298596 & 0.2 & 0.195 \\
\hline 6 & 135 & 0.22 & 0.75 & 2.03 & 507.906423 & 0.1 & 0.103 & 60 & 160 & 0.17 & 1.25 & 2.51 & 830.876766 & 0.3 & 0.295 \\
\hline 7 & 135 & 0.22 & 0.75 & 2.22 & 549.6707408 & 0.2 & 0.196 & 61 & 110 & 0.22 & 1.25 & 1.91 & 869.5817518 & 0 & 0.0069 \\
\hline 8 & 135 & 0.22 & 0.75 & 2.41 & 607.8317817 & 0.3 & 0.296 & 62 & 110 & 0.22 & 1.25 & 2.06 & 918.6134585 & 0.1 & 0.097 \\
\hline 9 & 160 & 0.22 & 0.75 & 1.92 & 425.9882627 & 0 & 0.0069 & 63 & 110 & 0.22 & 1.25 & 2.38 & 1071.060142 & 0.2 & 0.197 \\
\hline 10 & 160 & 0.22 & 0.75 & 2.1 & 461.3686162 & 0.1 & 0.103 & 64 & 110 & 0.22 & 1.25 & 2.59 & 1105.857864 & 0.3 & 0.303 \\
\hline 11 & 160 & 0.22 & 0.75 & 2.31 & 494.4350311 & 0.2 & 0.197 & 65 & 135 & 0.22 & 1.25 & 1.94 & 745.2126387 & 0 & 0.0071 \\
\hline 12 & 160 & 0.22 & 0.75 & 2.49 & 550.7640148 & 0.3 & 0.298 & 66 & 135 & 0.22 & 1.25 & 2.06 & 796.4092002 & 0.1 & 0.098 \\
\hline 13 & 110 & 0.17 & 0.75 & 1.87 & 488.4653561 & 0 & 0.00694 & 67 & 135 & 0.22 & 1.25 & 2.22 & 870.6964902 & 0.2 & 0.196 \\
\hline 14 & 110 & 0.17 & 0.75 & 2.11 & 542.4516931 & 0.1 & 0.103 & 68 & 135 & 0.22 & 1.25 & 2.49 & 911.0525741 & 0.3 & 0.303 \\
\hline 15 & 110 & 0.17 & 0.75 & 2.29 & 590.8054524 & 0.2 & 0.197 & 69 & 160 & 0.22 & 1.25 & 1.98 & 752.4570921 & 0 & 0.0067 \\
\hline 16 & 110 & 0.17 & 0.75 & 2.4 & 619.5714961 & 0.3 & 0.298 & 70 & 160 & 0.22 & 1.25 & 2.16 & 793.7415099 & 0.1 & 0.102 \\
\hline 17 & 135 & 0.17 & 0.75 & 1.89 & 431.1191696 & 0 & 0.00695 & 71 & 160 & 0.22 & 1.25 & 2.39 & 888.3170206 & 0.2 & 0.201 \\
\hline 18 & 135 & 0.17 & 0.75 & 2.01 & 457.529607 & 0.1 & 0.102 & 72 & 160 & 0.22 & 1.25 & 2.61 & & 0.3 & 0.297 \\
\hline 19 & 135 & 0.17 & 0.75 & 2.19 & 505.4190845 & 0.2 & 0.196 & 73 & 110 & 0.27 & 1.75 & 1.97 & 1381.07 & 0 & 0.0069 \\
\hline 20 & 135 & 0.17 & 0.75 & 2.38 & 542.4799135 & 0.3 & 0.296 & 74 & 110 & 0.27 & 1.75 & 12 & 1460.15 & 0.1 & 0.096 \\
\hline 21 & 160 & 0.17 & 0.75 & 1.88 & 421.4033879 & 0 & 0.00694 & 75 & 110 & 0.27 & 1.75 & 2.51 & 1542.516775 & 0.2 & 0.197 \\
\hline 22 & 160 & 0.17 & 0.75 & 2.03 & 461.4182598 & 0.1 & 0.101 & & 110 & 0.27 & 1.75 & & 1643.35 & 0.3 & 0.295 \\
\hline 23 & 160 & 0.17 & 0.75 & 2.22 & 513.6738995 & 0.2 & 0.197 & 77 & 135 & 0.27 & 1.75 & 2.01 & 1312.025489 & 0 & 0.0066 \\
\hline 24 & 160 & 0.17 & 0.75 & 2.39 & 566.2579763 & 0.3 & 0.295 & & 135 & 0.27 & 1.75 & 2.1 & 1390.799955 & 0.1 & 0.103 \\
\hline 25 & 110 & 0.27 & 0.75 & 1.91 & 605.464956 & 0 & 0.0071 & 79 & 135 & 0.27 & 1.75 & 2.3 & & 0.2 & 0.195 \\
\hline 26 & 110 & 0.27 & 0.75 & 2.21 & 670.7321351 & 0.1 & 0.102 & 80 & 135 & 0.2 & 1.75 & 2.6 & 1570.53505 & 0.3 & 0.2 \\
\hline 27 & 110 & 0.27 & 0.75 & 2.39 & 679.2722398 & 0.2 & 0.195 & 81 & 160 & 0.27 & 1.75 & 2.01 & 1239.966532 & 0 & 0.0075 \\
\hline 28 & 110 & 0.27 & 0.75 & 2.58 & 681.4264433 & 0.3 & 0.298 & 82 & 160 & 0.27 & 1.75 & 2.22 & 1318.344271 & 0.1 & 0.106 \\
\hline 29 & 135 & 0.27 & 0.75 & 1.91 & 578.6207739 & 0 & 0.0068 & 8 & 160 & 0.27 & 1.75 & 2.51 & 1373.1128 & 0.2 & 0.204 \\
\hline 30 & 135 & 0.27 & 0.75 & 2.09 & 609.4374455 & 0.1 & 0.103 & 84 & 160 & 0.27 & 1.75 & 2.72 & 1413.593272 & 0.3 & 0.296 \\
\hline 31 & 135 & 0.27 & 0.75 & 2.28 & 641.8808301 & 0.2 & 0.1 & & & 0.17 & 1.75 & & 941.9855529 & 0 & 0.0068 \\
\hline 32 & 135 & 0.27 & 0.75 & 2.48 & 662.4801884 & 0.3 & 0.298 & 87 & 110 & 0.17 & 1.75 & 2.41 & 1133.158 & 0.2 & 0.203 \\
\hline 33 & 160 & 0.27 & 0.75 & 1.94 & 564.6502556 & 0 & 0.0068 & 86 & 110 & 0.17 & 1.75 & 2.06 & 1030.021216 & 0.1 & 0.096 \\
\hline 34 & 160 & 0.27 & 0.75 & 2.15 & 585.6491377 & 0.1 & 0.101 & 88 & 110 & 0.17 & 1.75 & 2.6 & 1178.000535 & 0.3 & 0.304 \\
\hline 35 & 160 & 0.27 & 0.75 & 2.33 & 626.9278266 & 0.2 & 0.202 & 89 & 135 & 0.17 & 1.75 & 1.92 & 918.1398415 & 0 & 0.0082 \\
\hline 36 & 160 & 0.27 & 0.75 & 2.53 & 653.8333929 & 0.3 & 0.301 & 90 & 135 & 0.17 & 1.75 & 2.08 & 1023.888617 & 0.1 & 0.095 \\
\hline 37 & 110 & 0.27 & 1.25 & 1.93 & 928.5471262 & 0 & 0.0062 & 91 & 135 & 0.17 & 1.75 & 2.23 & 1128.235 & 0.2 & 0.195 \\
\hline 38 & 110 & 0.27 & 1.25 & 2.09 & 956.3385088 & 0.1 & 0.105 & 92 & 135 & 0.17 & 1.75 & 2.5 & 1164.430332 & 0.3 & 0.301 \\
\hline 39 & 110 & 0.27 & 1.25 & 2.45 & 1000.902305 & 0.2 & 0.196 & 93 & 160 & 0.17 & 1.75 & 1.94 & 891.9758965 & 0 & 0.0067 \\
\hline 40 & 110 & 0.27 & 1.25 & 2.64 & 1054.147666 & 0.3 & 0.296 & 94 & 160 & 0.17 & 1.75 & 2.16 & 983.5141077 & 0.1 & 0.101 \\
\hline 41 & 135 & 0.27 & 1.25 & 1.96 & 863.3643016 & 0 & 0.00722 & 95 & 160 & 0.17 & 1.75 & 2.39 & 1089.082641 & 0.2 & 0.2 \\
\hline 42 & 135 & 0.27 & 1.25 & 2.09 & 921.2229525 & 0.1 & 0.103 & 96 & 160 & 0.17 & 1.75 & 2.6 & 1133.880505 & 0.3 & 0.301 \\
\hline 43 & 135 & 0.27 & 1.25 & 2.26 & 967.0207161 & 0.2 & 0.197 & 97 & 110 & 0.22 & 1.75 & 1.95 & 1183.488707 & 0 & 0.0075 \\
\hline 44 & 135 & 0.27 & 1.25 & 2.56 & 1000.436551 & 0.3 & 0.298 & 98 & 110 & 0.22 & 1.75 & 2.07 & 1291.051105 & 0.1 & 0.102 \\
\hline 45 & 160 & 0.27 & 1.25 & 1.96 & 806.514104 & 0 & 0.0074 & 99 & 110 & 0.22 & 1.75 & 2.45 & 1337.684274 & 0.2 & 0.196 \\
\hline 46 & 160 & 0.27 & 1.25 & 2.17 & 871.29157 & 0.1 & 0.101 & 100 & 110 & 0.22 & 1.75 & 2.73 & 1353.697416 & 0.3 & 0.301 \\
\hline 47 & 160 & 0.27 & 1.25 & 2.36 & 925.3075165 & 0.2 & 0.203 & 101 & 135 & 0.22 & 1.75 & 1.99 & 1159.960631 & 0 & 0.00827 \\
\hline 48 & 160 & 0.27 & 1.25 & 2.57 & 962.1112202 & 0.3 & 0.304 & 102 & 135 & 0.22 & 1.75 & 2.11 & 1241.587415 & 0.1 & 0.103 \\
\hline 49 & 110 & 0.17 & 1.25 & 1.89 & 670.5687521 & 0 & 0.0072 & 103 & 135 & 0.22 & 1.75 & 2.28 & 1290.81065 & 0.2 & 0.197 \\
\hline 50 & 110 & 0.17 & 1.25 & 2.03 & 711.5042912 & 0.1 & 0.098 & 104 & 135 & 0.22 & 1.75 & 2.55 & 1326.516853 & 0.3 & 0.296 \\
\hline 51 & 110 & 0.17 & 1.25 & 2.34 & 796.2878718 & 0.2 & 0.197 & 105 & 160 & 0.22 & 1.75 & 1.97 & 1151.613924 & 0 & 0.0068 \\
\hline 52 & 110 & 0.17 & 1.25 & 2.51 & 857.1547418 & 0.3 & 0.297 & 106 & 160 & 0.22 & 1.75 & 2.19 & 1224.685614 & 0.1 & 0.104 \\
\hline 53 & 135 & 0.17 & 1.25 & 1.91 & 639.6655376 & 0 & 0.0068 & 107 & 160 & 0.22 & 1.75 & 2.43 & 1260.990692 & 0.2 & 0.197 \\
\hline 54 & 135 & 0.17 & 1.25 & 2.03 & 697.5514318 & 0.1 & 0.102 & 108 & 160 & 0.22 & 1.75 & 2.68 & 1287.31628 & 0.3 & 0.298 \\
\hline
\end{tabular}


Table 2. Geometric specifications of the cutting tool.

\begin{tabular}{cccccc}
\hline Insert & \multicolumn{5}{c}{ Sandvik TNMG 16 04 04-QM H13A } \\
\hline \multirow{2}{*}{$\begin{array}{c}\text { Geometric } \\
\text { values }\end{array}$} & $\begin{array}{c}\text { Insert thickness } \\
(S)\end{array}$ & $\begin{array}{c}\text { I.C size } \\
(I C)\end{array}$ & $\begin{array}{c}\text { Nose radius } \\
(R E)\end{array}$ & $\begin{array}{c}\text { Insert weight } \\
(W T)\end{array}$ & $\begin{array}{c}\text { Cutting edge length } \\
\text { nyyyyy}\end{array}$ \\
\cline { 2 - 6 } & $4.7625 \mathrm{~mm}$ & $9.525 \mathrm{~mm}$ & $0.4 \mathrm{~mm}$ & $0.007 \mathrm{~kg}$ & $16.4978 \mathrm{~mm}$ \\
\hline
\end{tabular}

Table 3. Chemical properties of the work piece.

\begin{tabular}{cccccccc}
\hline Work piece & \multicolumn{7}{c}{ SAE 4140 (AISI 4140) } \\
\hline Chemical & $\mathbf{C}$ & Si & Mn & Cr & P & S & Mo \\
\cline { 2 - 8 } compositions & 0.38 & 0.15 & 0.75 & 0.80 & 0.035 & 0.04 & 0.15 \\
$(\%)$ & -0.43 & -0.30 & -1.00 & -1.10 & & & -0.25 \\
\hline
\end{tabular}

Table 4. Mechanical properties of the material.

\begin{tabular}{|c|c|c|c|c|c|c|}
\hline Work piece & & & SAE 4140 & SI 4140) & & \\
\hline \multirow{2}{*}{$\begin{array}{l}\text { Properties of } \\
\text { the material }\end{array}$} & $\begin{array}{c}\text { Tensile strength } \\
(\mathrm{MPa})\end{array}$ & $\begin{array}{l}\text { Yield strength } \\
(\mathrm{MPa})\end{array}$ & Treatment & $\begin{array}{c}\text { Hardness } \\
(H B)\end{array}$ & $\begin{array}{c}\text { Impact strength } \\
J(\text { Izod })\end{array}$ & $\begin{array}{c}\text { Elastic resistivity } \\
\quad\left(10^{-9} \Omega-\mathrm{m}\right)\end{array}$ \\
\hline & 655 & 417.1 & Annealed at $815^{\circ} \mathrm{C}$ & 197 & 54.5 & 222 \\
\hline
\end{tabular}

rial are given in Tables 3 and 4 . A Dino Capture microscope was applied to measure the flank wear during the test conducting. A TV300 type vibration sensor was used for measuring the vibration signal amplitudes. To evaluate the vibration conditions, the displacement, acceleration and velocity variables can be measured by the sensor. The sensor measures the Root Mean Square (RMS) of the variables. The accelerations between $10 \mathrm{~Hz}-10 \mathrm{KHz}$ were measured as the monitoring variable in this study. The signals were received from cutting region and transferred to data viewer program for the analysis of the results. Cutting forces were measured using a Kistler 9272 4component dynamometer in three directions including $F_{c}$ (cutting force), $F_{t}$ (thrust force), and $F_{r}$ (radial force). Tool flank wear values were measured on the clearance face between $0-0.3$ for a new and worn tool, respectively, based on ISO3685 standard. Figure 2 shows the experimental setup of the tests.

The tool flank wear $\left(V_{b}\right)$ limits were selected from 0 to $0.3 \mathrm{~mm}$ as: $0,0.1,0.2,0.3 \mathrm{~mm}$ for new, relatively worn, highly worn, and worn out tools before starting the tests. By applying the wear values and full factorial method, a total of 108 experiments were conducted to measure the magnitude of cutting force and vibration amplitude during the machining process. The experiments have been conducted in different cutting speeds $(V)$, cutting depth $(d)$, cutting feed $(f)$, cutting force $(F)$, and vibration amplitude $(a)$. As mentioned earlier, among the measured variables by the vibration sensor, the amplitudes of the acceleration signals were saved and used for tool wear monitoring. Indeed, there are three forces in the machining area including $F_{c}$ (cutting force), $F_{t}$ (thrust force), and $F_{r}$

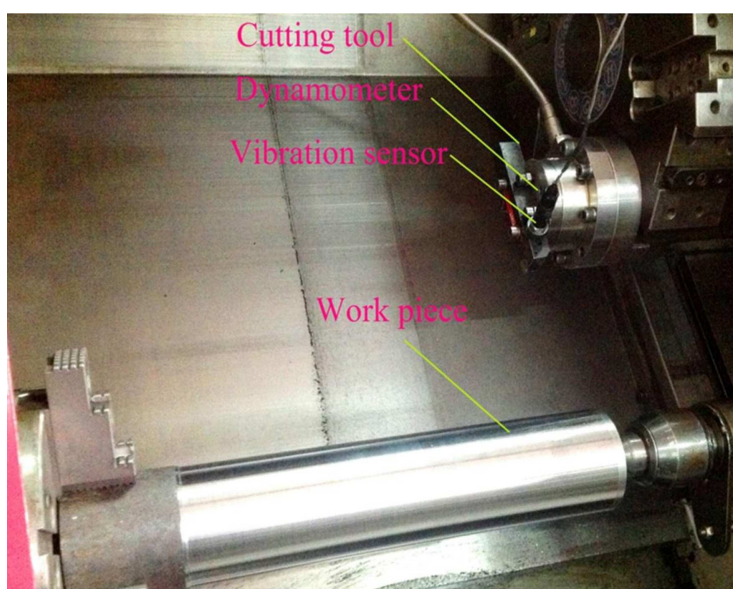

Figure 2. Experimental setup of the tests on CNC machine tool including dynamometer and vibration sensor.

(radial force), resulting from the metal cutting process. The value of the resultant cutting force was used as the cutting force variable in tool wear monitoring as follows:

$$
F=\sqrt{F_{c}^{2}+F_{t}^{2}+F_{r}^{2}}
$$

\section{Artificial neural networks}

Neural networks are data processing systems consisting of a large number of simple, highly interconnected artificial neurons in an architecture inspired by the structure of the brain. They have the ability to learn from the experience in order to improve their performance and to adapt themselves to changes in the environment $[26,27]$. 


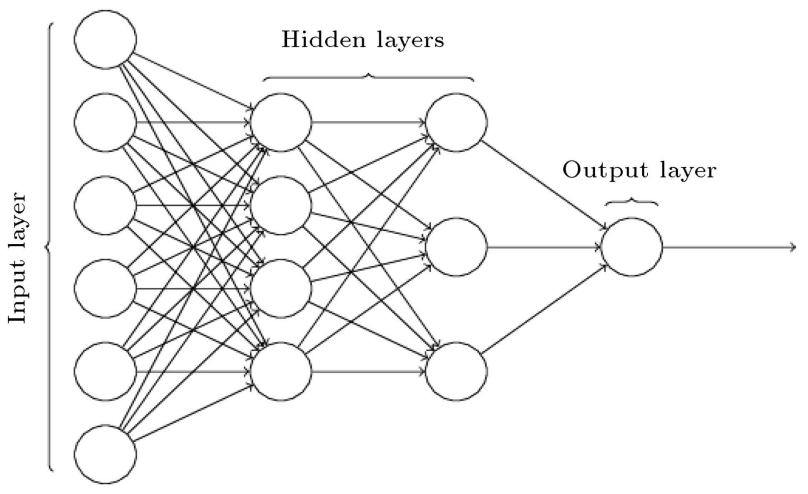

Figure 3. Architecture of a typical multi-layer feedforward neural network.

The typical network has 1 input layer, 1 or more hidden layers, and 1 output layer. Each layer has some units corresponding to neurons. The units in neighboring layers are fully interconnected with links corresponding to synapses. The strengths of the connections between 2 units are called "weights." The back propagation neural network model is one of the most commonly used ANN models, whose application stretches to almost every field of the sciences. As shown in Figure 3, a typical back propagation neural network has three layers: the input layers, the hidden layers, and the output layers. The optimization procedure of the network is conducted by training the network based on the experiments. The method employed in the training of the ANN may depend upon the ANN architecture, the intended purpose of the ANN, and even the resources available in developing the system. The used method in this study, i.e. supervised learning, implies that there is prior knowledge of the system to be modelled in the form of input-output pairs. Therefore, the conducted experiments are used to estimate the output values.

In every hidden and output layers, the processing unit sums its input from the previous layer, and then applies the activation function to compute its output to the next layer according to the following equations [28]:

$$
v=\sum_{i=0}^{n} w_{i j} x_{i}, \quad \text { or } \quad v=\sum_{i=0}^{n} w_{i j} x_{i}+b
$$

where $w_{i j}$ is the weight from node $i$ in the input layer to node $j$ in the hidden layer; $x_{i}$ is the $i$ th input element; $n$ is the number of nodes in the input layer. In the first stage, the values of weights are selected arbitrarily. After obtaining the results, a nonlinear activation function is used to regulate the output of a node, shown as follows:

$$
y=F(v)
$$

where $F(v)$ is the output of the $j$ th node in the hidden layer. Subsequently, output from the hidden layer is used as inputs to the output node. Finally, the overall response from the network is obtained via the output node in the output layer. The sum of error squares for the $n$th iteration is defined as [28]:

$$
\sum_{i=1}^{k} E_{i}=\frac{1}{2} \sum_{i=1}^{k}\left(h_{i}-y_{i}\right)^{2}
$$

where $\left(h_{i}-y_{i}\right)^{2}$ square of error is signal at the output neuron and is the difference between desired response (h) and computed response $(y)$. Based on the errors, the weights are updated in such a way that the error signal is minimized to the required threshold.

After training the network and obtaining the weights, all of the parameters are normalized and adjusted between 0 and 1 . The weights of the first layers are applied into Eq. (2) to aggregate the neuron values.

Then, the results of the above equation are substituted into the following equation to obtain the activated value.

$$
F(v)=\frac{2}{\left(1+e^{(-2 \times v)}\right)}-1 .
$$

The above mentioned process is conducted for all of the connections, and the results of the activation function are assigned to the neurons of the second layer. The same process is continued for the second and third layers to find the predicted result of the first experiment.

For activating the values of any neuron, an activation function is applied to ANN modeling. There are many activation functions used in modeling the linear and nonlinear incidents. However, hyperbolic tangent sigmoid (Tansig) and linear function (Purelin) are the most common used activation functions. Hyperbolic tangent sigmoid represents a nonlinear function as follows:

$$
T=\frac{2}{\left(1+e^{(-2 \times x)}\right)}-1 .
$$

Also, the linear function is defined as follows:

$$
P= \begin{cases}1 & x>1 \\ & x-1<x>1 \\ -1 & x<-1\end{cases}
$$

The diagrams of the tansig and purelin activation functions are given in Figure 4.

\section{Results and discussion}

\subsection{ANN modeling}

For accurately selecting the input parameters for ANN model, an analysis should be used to determine the 
Table 5. ANOVA effect tests.

\begin{tabular}{lccccc}
\hline \multicolumn{1}{c}{ Parameters } & Nparm & DF & Sum of squares & $\boldsymbol{F}$ ratio & Prob $>\boldsymbol{F}$ \\
\hline Cutting speed, $V(\mathrm{~m} / \mathrm{min})$ & 1 & 1 & 0.03545450 & 18.4915 & $<0.0001$ \\
Cutting feed, $f(\mathrm{~mm} / \mathrm{rev})$ & 1 & 1 & 0.17786155 & 92.7646 & $<0.0001$ \\
Cutting depth, $d(\mathrm{~mm})$ & 1 & 1 & 0.14689249 & 76.6125 & $<0.0001$ \\
Resultant cutting force, $F(\mathrm{~N})$ & 1 & 1 & 0.12922667 & 67.3988 & $<0.0001$ \\
Vibration amplitude, $a\left(\mathrm{~m} / \mathrm{s}^{2}\right)$ & 1 & 1 & 0.12594594 & 65.6877 & $<0.0001$ \\
\hline
\end{tabular}
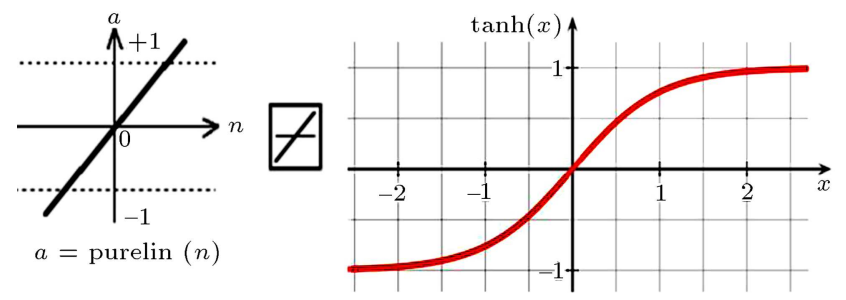

Figure 4. Diagrams of the tansig and purelin activation functions.

significant parameter influencing the tool wear [29]. Therefore, the effects of parameters were examined on tool flank wear by taking advantage of the ANOVA analysis. As shown in Table 5 , since the $P$-value for all inputs is less than 0.05 , the effects of all materials on tool flank wear are meaningful. However, the maximum $F$-ratio for cutting feed (92.76) among the cutting parameters and the highest $F$-ratio for the cutting force (67.39) among the variables were found as the most effective factors.

As is obvious in Table 5 , the $P$-values for all of the considered inputs in statistical analyses are under 0.05 . It means that the selected variables are meaningful in the estimation of tool wear rates. Therefore, these variables were selected as input values to design the ANN model of the tool wear prediction system. In order to create the ANN model, three cutting parameters, including cutting speed $(V)$, cutting depth $(d)$, and cutting feed $(f)$ and also control variables, including the vibration amplitude $(a)$ and cutting force $(F)$, were entered into the system as input parameters. Also, the tool flank wear was defined as output parameters. The cutting parameters were selected based on the mentioned standard, and the control variables were measured using vibration and cutting force sensors during the machining operation. For creating the model, three-layer feedforward neural network (newff) was selected as the network. Different algorithms were tested for training and 'Levenberg-Marquadt' was preferred as the optimal one. 21 neurons and 1400 epoch number were selected for designing the model. The numbers of neurons located in the first, second, and third layers are 14, 6, and 1, respectively. "Tansig", "Purline" and "Purline" functions were used as activation functions among input and first, first and second, and second and third layers, respectively. The

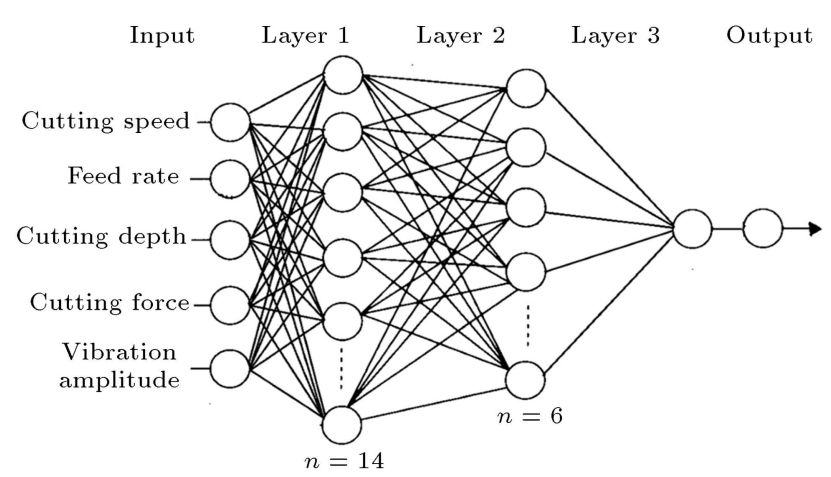

Figure 5. The structure of the developed ANN model.

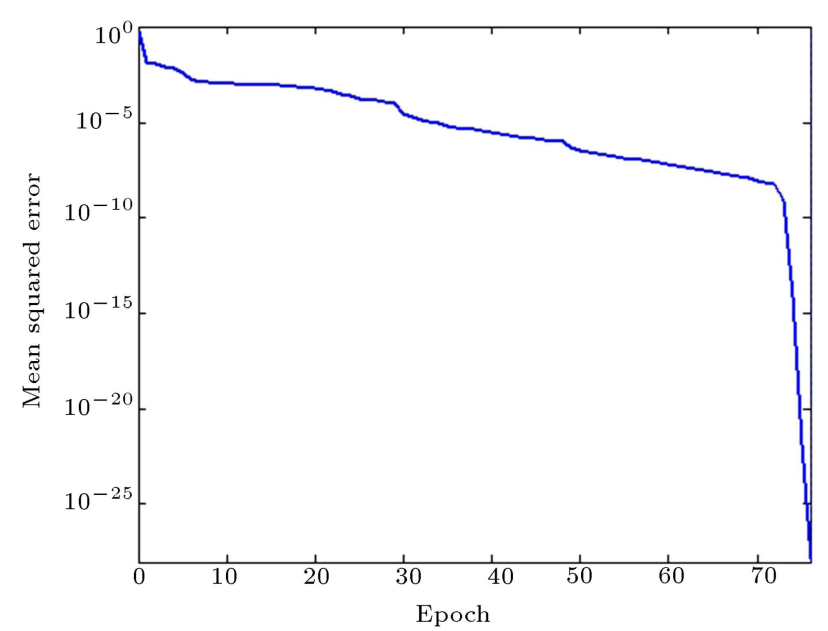

Figure 6. Error reduction during the training process.

structure of the designed artificial model is shown in Figure 5.

Based on the defined parameters and ANN structure, the training was conducted using a developed program in MATLAB. During the training period, the decreasing rate of the squared error between the target and the estimated value is shown in Figure 6. According to the figure, training chart varies with the increase of the epoch size. The ANN trainer program in the first step selects the weights randomly and adjusts the weights after obtaining the results and comparing them with the real results. Adjusting process continues until reaching a minimum error. The training process was conducted too many times to reach a good fitting diagram without any overfitting or overtraining. For creating the ANN model, $70 \%$ of the experiments are 
Table 6. Weight values for the first layer.

\begin{tabular}{cccccc}
\hline \multirow{2}{*}{ Weights } & \multicolumn{5}{c}{ Number of inputs } \\
\cline { 2 - 6 } & $\mathbf{1}$ & $\mathbf{2}$ & $\mathbf{3}$ & $\mathbf{4}$ & $\mathbf{5}$ \\
\hline$w_{1,1}$ & -1.97074177 & 18.3546981059298 & 0.0334895472648057 & 0.0013590785549760 &,- 1.944069036241 \\
$w_{1,2}$ & 2.88914032 & 19.7055115697428 & 0.0391651527827321 & 0.0014170179388367 & 0.4999694573194 \\
$w_{1,3}$ & -1.77086886 & -18.877158745686 & 0.0728794019676506 & 0.0003879983576415 & -1.9587552527737 \\
$w_{1,4}$ & -3.4779353 & 0.79486056997682 & -0.086904724119701 & 0.0054379373306922 & 2.4616544158284 \\
$w_{1,5}$ & 1.59241309 & -4.4059792586338 & 0.0024586022213639 & -0.0095617136547518 & 2.6309216664133 \\
$w_{1,6}$ & -0.65575505 & -19.732238115851 & -0.046961827356179 & -0.0009893966123647 & -3.1520155770673 \\
$w_{1,7}$ & -1.73035579 & 21.6751055971839 & -0.097610509456990 & 0.0081464456259026 & 0.9672802099854 \\
$w_{1,8}$ & -2.69758207 & 28.1249098957808 & 0.0574501628469547 & -0.0020104194798799 & -1.3731700552428 \\
$w_{1,9}$ & -2.17063471 & 6.99520230121540 & 0.0200817137638607 & 0.0028928931160888 & 2.7061477430860 \\
$w_{1,10}$ & -0.92824786 & -36.315619596745 & 0.0287517183324107 & -0.0064612706451211 & 1.9261638427807 \\
$w_{1,11}$ & -3.61038965 & -20.392373602904 & -0.044040045145653 & 0.0053617773296879 & -1.8614153299422 \\
$w_{1,12}$ & 2.63746593 & 20.2416707237956 & $8.99905974557 \mathrm{e}-005$ & -0.0072943525986559 & -1.8581084043978 \\
$w_{1,13}$ & -0.51526015 & -21.935223301000 & 0.4510180492263223 & -0.1218730340949915 & 2.8837186862469 \\
$w_{1,14}$ & -0.59471770 & -15.192789805593 & 0.0106622343722436 & 0.0027952230927028 & 3.2082025479812 \\
\hline
\end{tabular}

used for training, $15 \%$ are kept for testing, and $15 \%$ for validation. For establishing an online prediction model, all of the obtained weights and bias values during the training are saved and used in mathematical model and program.

The model structure has 5 inputs connected to 14 neurons in the first layer. Therefore, there will be a total of 70 connections between the inputs and the first layer neurons. It implies that the number of weights for the first layer is 70 and the number of biases is 14 . All of the estimated weights and all bias values of the first layer are given in Tables 6 and 7 , respectively. In Table 6 , the $i$ indices shows the number of layer and $j$ shows the number of first layer neurons.

There are 14 and 6 neurons in the first and second layers, respectively. Therefore, there are a total of 84 connections between the first layer and the second layer. It is implied that there are 84 weights and 6 biases in the second layer needed to formulate the results of the second layer neurons. All available 84 weight values are given in Table 8 . Also, the bias values that must be gathered by weight values are given in Table 9.

The number of weights in the third layer is 6 based on 6 connections between the second and third layers due to 6 neurons in the second layer and 1 neuron in the third layer. Also, there is only 1 bias value which is equal to 1 neuron in the last layer. The weight and bias values of the last or third layer are given in Table 10.

Making an ANN prediction model is a timeconsuming process due to a large number of weight and bias values. To eliminate this process, the simulation
Table 7. Bias values for the first layer.

\begin{tabular}{cc}
\hline Biases & First layer \\
\hline$B_{1}$ & -7.0789329969940793 \\
$B_{2}$ & 2.5179018818487413 \\
$B_{3}$ & 4.7485242378162704 \\
$B_{4}$ & 6.6937787138683325 \\
$B_{5}$ & 3.1640591505230589 \\
$B_{6}$ & 18.628574291499405 \\
$B_{7}$ & -1.0110257151509474 \\
$B_{8}$ & -4.9142447720322169 \\
$B_{9}$ & -10.498695451961783 \\
$B_{10}$ & 5.4051552263109226 \\
$B_{11}$ & 13.852649299020378 \\
$B_{12}$ & 4.5307357794522964 \\
$B_{13}$ & 5.1769721889169595 \\
$B_{14}$ & -6.1287801118826621 \\
\hline
\end{tabular}

model of the developed ANN model was designed as a block diagram. In this block diagram, the cutting parameters are given in the model and the cutting forces and vibration amplitudes received from sensors are applied as the variables to the input of the simulation model. The tool flank wears are then predicted and shown as the model result. The simulation model can also be applied to machine tool adaptive control and automated manufacturing systems. The block diagram and the simulation result for a certain values of the cutting parameters are given in Figure 7 . Based on the 
Table 8. Weight values for the second layer.

\begin{tabular}{|c|c|c|c|c|c|c|}
\hline \multirow{2}{*}{$\begin{array}{l}\text { Number of second } \\
\text { layer neurons }\end{array}$} & \multicolumn{6}{|c|}{ Weights } \\
\hline & $w_{2,1}$ & $w_{2,2}$ & $w_{2,3}$ & $w_{2,4}$ & $w_{2,5}$ & $w_{2,6}$ \\
\hline 1 & -0.249161 & 1.7165847141 & 1.51623360164 & -0.160327461704 & -0.553972842280 & 0.1148804747 \\
\hline 2 & -1.386316 & 0.0223005780 & 0.80393850731 & -0.671652702282 & 0.3276705925057 & 0.1891440784 \\
\hline 3 & -0.447742 & -0.756985057 & -1.01702360063 & -0.112111758000 & 0.7167586521491 & -0.863314389 \\
\hline 4 & -0.685702 & -0.078538124 & -0.91098573606 & -0.842465704700 & 0.2181940845534 & 0.9927338719 \\
\hline 5 & -0.207756 & 0.1093681865 & -0.65271439051 & 0.2279751827289 & -0.193874069576 & 1.2848288166 \\
\hline 6 & -0.761786 & 0.0248821859 & -0.11074540659 & -0.540133363614 & -0.016166519042 & -1.361348065 \\
\hline 7 & -0.824518 & -0.304871896 & -0.59492771273 & 0.5075889503368 & -0.233226430791 & 1.1358160454 \\
\hline 8 & 0.5495813 & -0.048972786 & 1.86236362547 & 0.3216769985963 & -0.008963779130 & 1.0877815214 \\
\hline 9 & -0.373099 & 0.4000200685 & -1.38351256835 & 0.9121855468975 & -0.444833258690 & -0.628093320 \\
\hline 10 & 1.6219110 & 0.0042583521 & -0.85723804008 & -0.744670482205 & 0.5054538646639 & 1.1993671841 \\
\hline 11 & 0.5820378 & 0.1755388856 & -1.00767355397 & 1.4699866632162 & -0.503951268593 & -0.533127176 \\
\hline 12 & 0.0946864 & 0.2523338025 & -0.36396884778 & 0.4435617981503 & 0.1535519729778 & -2.003687298 \\
\hline 13 & -0.124563 & 0.4437133763 & -1.12761881920 & 0.0994813607436 & 0.4269724928679 & 0.0599503575 \\
\hline 14 & 0.5754625 & 0.0369025283 & 0.67921273499 & -1.210346010927 & 0.0156948625931 & -0.897582821 \\
\hline
\end{tabular}

Table 9. Bias values for the second layer.

\begin{tabular}{cc}
\hline Bias & Second layer \\
\hline$B_{1}$ & -2.5385669124682031 \\
$B_{2}$ & -1.6659015715359653 \\
$B_{3}$ & -0.2173213072485988 \\
$B_{4}$ & 0.83509230203994311 \\
$B_{5}$ & -0.89746047923562522 \\
$B_{6}$ & -1.7677705247849465 \\
\hline
\end{tabular}

simulated result, the tool flank wear increases during the machining process.

Graphical simulation of the model is given in Figure 8. As seen in the figure, the tool flank wear values are constant in relation to the cutting parameters, while they are increasing by making any increase in the cutting forces. The fitting graphic of the model for all of the experiments resulted from the simulation model is also given in Figure 8. Based on the ANN simulation model, the predicted and measured diagrams overlap each other.

Distribution of the errors was simulated, illustrated in Figure 9. As seen in the figure, the errors are ignorable. It means that the model can predict the results with almost no error. According to the all experiments input, fitting graphics of the predicted values are also given in Figure 9. Once again, it has been determined that the errors values are so low and so close to zero. As a result of this prediction system, when the values are compared, $R^{2}$ value was obtained as 1 . In comparison to the other mathematical prediction methods, artificial neural networks demonstrate a little more reliability when the training is conducted with a large number of the experiments. The comparison of performances of ANN, fuzzy logic, and mathematical models has been discussed in detail in a study published by the authors of this paper [30].

Table 10. Weight and bias values for the third layer.

\begin{tabular}{cccc}
\hline Number of third & Weights & Bias & Third layer \\
\cline { 2 - 3 } layer neurons & $\boldsymbol{w}_{\mathbf{3}, \mathbf{1}}$ & & \\
\hline 1 & 0.018378636412932706 & & \\
2 & -0.071468766806288497 & & \\
3 & 0.34486231546358831 & $B 1$ & 0.94136400108751483 \\
4 & -0.15022510933066349 & & \\
5 & -0.31887119866466068 & & \\
6 & 0.70814248154860204 & & \\
\hline
\end{tabular}



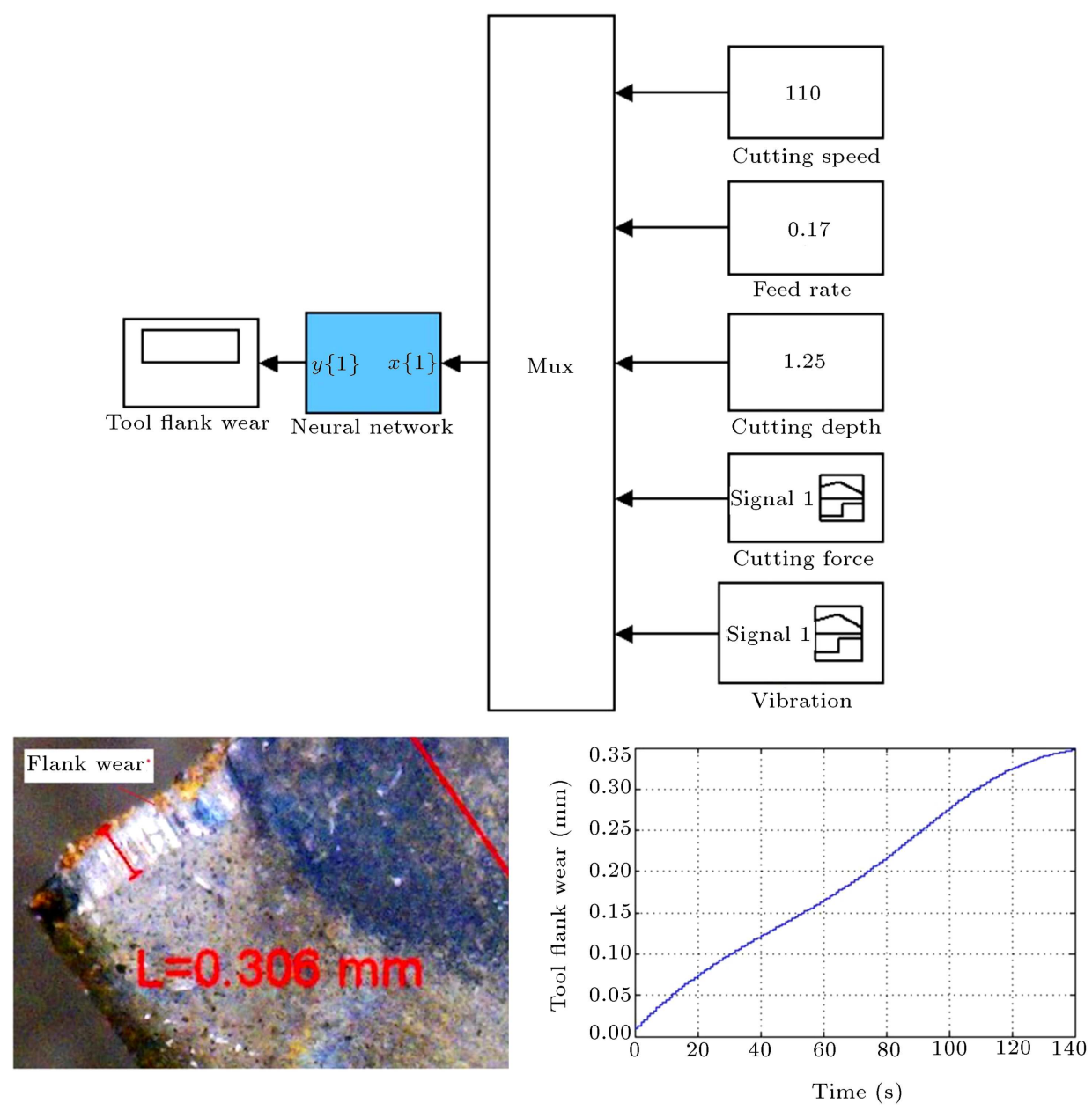

Figure 7. Block diagram of the model and the simulated result for $v=110 \mathrm{~m} / \mathrm{min}, d=1.25 \mathrm{~mm}$ and $f=0.17 \mathrm{~mm} / \mathrm{rev}$.
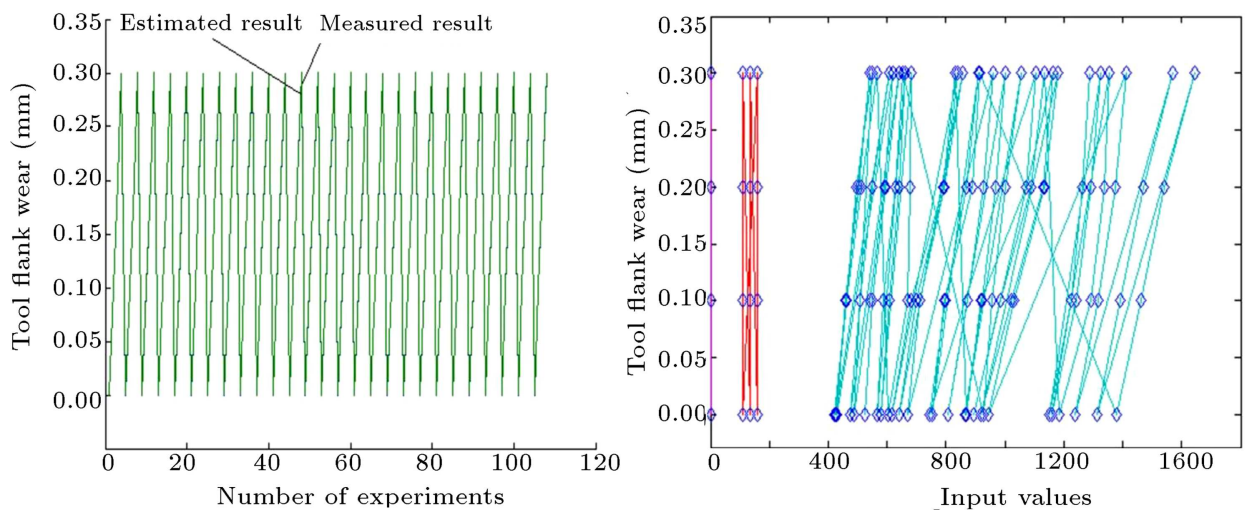

Figure 8. Graphical simulation of the model for all of the input parameters and estimated and measured results.

\section{Conclusion}

An ANN model was developed to predict the tool flank wear and to simulate the wear process in turning in this study. The results represented that ANN is a robust and reliable tool for predicting the tool wear rate in machining operations. Moreover, it was found that online monitoring of the tool wear rate is possible by creating a simulation model of the ANN.
In this simulation model, the cutting parameters are selected and the cutting force and vibration data are received from the sensors and given to the model as input parameters during the cutting process. By processing the data, the wear rates are estimated online in a real-time mode. Furthermore, one of the most important applications of the simulated model is in establishing the Flexible Manufacturing Systems (FMS) and Computer-Integrated Manufacturing sys- 

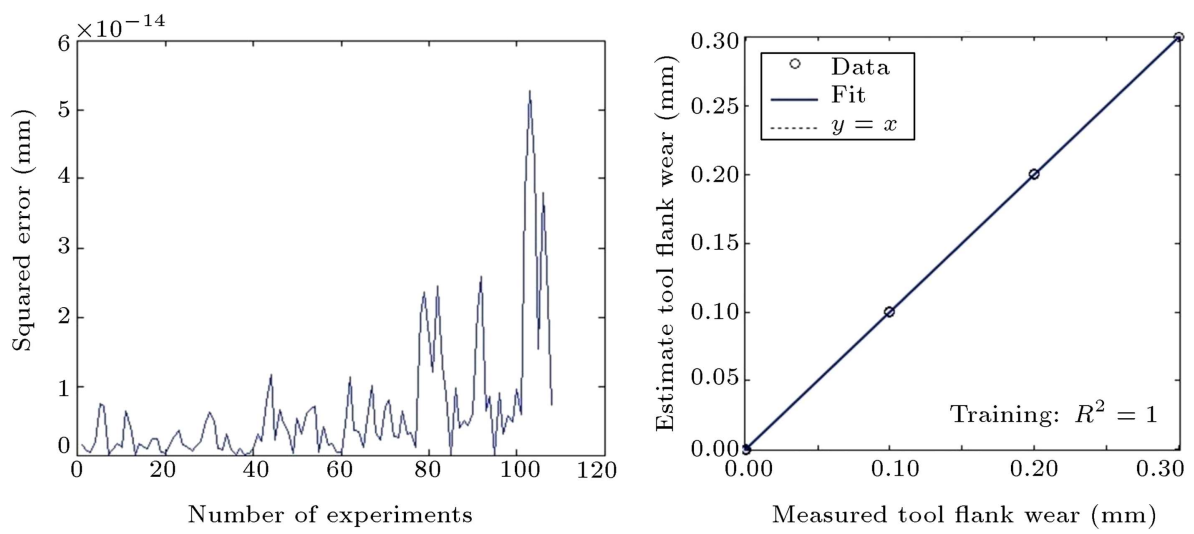

Figure 9. The result comparisons and error distributions.

tems (CIM). This model can be used as a useful method for conducting the adaptive control systems on the machine tools. The developed model in this study can be used in small manufacturing workshops due to its user-friendly specification. Using multi-sensor system for developing a tool wear monitoring model is one of the other specifications of this study in which the highly reliable and accurate results are achieved. In this designed model, the obtained $\mathrm{R} 2$ value in comparison with the result is 1 , confirming the model accuracy.

\section{Acknowledgment}

The authors would like to thank the Machine Tool Laboratories of Technology Faculty of Gazi University.

\section{References}

1. Sick, B. "On-line and indirect tool wear monitoring in turning with artificial neural networks: a review of more than a decade of research", Mechanical Systems and Signal Processing, 16(4), pp. 487-546 (2002).

2. Kurada, S. and Bradley, C. "A machine vision system for tool wear assessment", Tribology International, 30(4), pp. 295-304 (1997).

3. Scheffer, C. and Heyns, P.S. "Wear monitoring in turning operations using vibration and strain measurements", Mechanical Systems and Signal Processing, 15(6), pp. 1185-1202 (2001).

4. Balazinski, M., Czogala, E., Jemielniak, K. and Leski, J. "Tool condition monitoring using artificial intelligence methods", Engineering Applications of Artificial Intelligence, 15(1), pp. 73-80 (2002).

5. Kasashima, N., Mori, K., Ruiz, G.H. and Taniguchi, N. "Online failure detection in face Milling using discrete wavelet transform", CIRP Annals - Manufacturing Technology, 44(1), pp. 483-487 (1995).

6. Bhattacharyya, P., Sengupta, D. and Mukhopadhyay, S. "Cutting force-based real-time estimation of tool wear in face milling using a combination of signal processing techniques", Mechanical Systems and Signal Processing, 21(6), pp. 2665-2683 (2007).
7. Mohanraj, M., Jayaraj, S. and Muraleedharan, C. "Applications of artificial neural networks for refrigeration, air-conditioning and heat pump systems - A review", Renewable and Sustainable Energy Reviews, 16(2), pp. 1340-1358 (2012).

8. Mohanraj, M., Jayaraj, S. and Muraleedharan, C. "Applications of artificial neural networks for thermal analysis of heat exchangers - A review", International Journal of Thermal Sciences, 90, pp. 150-172 (2015).

9. Bukkapatnam, S.T.S., Kumara, S.R.T. and Lakhtakia, A. "Fractal estimation of flank wear in turning", Journal of Dynamic Systems, Measurement, and Control, 122(1), pp. 89-94 (2000).

10. Lin, J.T., Bhattacharyya, D. and Kecman, V. "Multiple regression and neural networks analyses in composites machining", Composites Science and Technology, 63(3-4), pp. 539-548 (2003).

11. Deiab, I., Assaleh, K. and Hammad, F. "On modeling of tool wear using sensor fusion and polynomial classifiers", Mechanical Systems and Signal Processing, 23(5), pp. 1719-1729 (2009).

12. Dong, J., Subrahmanyam, K.V.R., Wong, Y.S., Hong, G.S. and Mohanty, A.R. "Bayesian-inference-based neural networks for tool wear estimation", International Journal of Advanced Manufacturing Technology, 30(9-10), pp. 797-807 (2006).

13. U. Zuperl, F.C. and Balic, J. "Intelligent cutting tool condition monitoring in milling", Journal of Achievements in Materials and Manufacturing Engineering, 49(2), pp. 477-486 (2011).

14. Ertekin, Y.M., Kwon, Y. and Tseng, T.-L. "Identification of common sensory features for the control of CNC milling operations under varying cutting conditions", International Journal of Machine Tools and Manufacture, 43(9), pp. 897-904 (2003).

15. Chen, S.-L. and Jen, Y.W. "Data fusion neural network for tool condition monitoring in CNC milling machining", International Journal of Machine Tools and Manufacture, 40(3), pp. 381-400 (2000).

16. Liu, Y. and Wang, C. "Neural network based adaptive control and optimization in the milling process", International Journal of Advanced Manufacturing Technology, 15(11), pp. 791-795 (1999). 
17. Yusuf, A. "In-process detection of tool breakages using time series monitoring of cutting forces", International Journal of Machine Tools and Manufacture, 28(2), pp. 157-172 (1988).

18. Zhang, J. and Chen, J. "The development of an inprocess surface roughness adaptive control system in end milling operations", The International Journal of Advanced Manufacturing Technology, 31(9), pp. 877887 (2007).

19. Benardos, P.G. and Vosniakos, G.C. "Prediction of surface roughness in CNC face milling using neural networks and Taguchi's design of experiments", Robotics and Computer-Integrated Manufacturing, 18(5-6), pp. 343-354 (2002).

20. Azouzi, R. and Guillot, M. "On-line prediction of surface finish and dimensional deviation in turning using neural network based sensor fusion", International Journal of Machine Tools and Manufacture, 37(9), pp. 1201-1217 (1997).

21. El Ouafi, A., Guillot, M. and Bedrouni, A. "Accuracy enhancement of multi-axis CNC machines through online neurocompensation", Journal of Intelligent Manufacturing, 11(6), pp. 535-545 (2000).

22. Byrne, G., Dornfeld, D. and Denkena, B. "Advancing cutting technology", CIRP Annals - Manufacturing Technology, 52(2), pp. 483-507 (2003).

23. Kilundu, B., Dehombreux, P. and Chiementin, X. "Tool wear monitoring by machine learning techniques and singular spectrum analysis", Mechanical Systems and Signal Processing, 25(1), pp. 400-415 (2011).

24. Ding, F. and He, Z. "Cutting tool wear monitoring for reliability analysis using proportional hazards model", The International Journal of Advanced Manufacturing Technology, 57(5-8), pp. 565-574 (2011).

25. Noh, M.-S. and Hong, D. "Implementation of remote monitoring system for prediction of tool wear and failure using ART2", Journal of Central South University of Technology, 18(1), pp. 177-183 (2011).

26. Schabowicz, J.H.K. "Application of artificial neural networks to determine concrete compressive strength based on non-destructive tests", Journal of Civil Engineering and Management, 1(11), pp. 22-31 (2005).

27. Mansour, M.Y., Dicleli, M., Lee, J.Y. and Zhang, J. "Predicting the shear strength of reinforced concrete beams using artificial neural networks", Engineering Structures, 26(6), pp. 781-799 (2004).

28. Salimi, A., Özdemir, A. and Safarian, I. "Designing an artificial neural network based model for online prediction of tool life in turning", International Journal of Advanced Design and Manufacturing Technology, 8(2), pp. 65-71 (2015).

29. Gunasekar, N., Mohanraj, M. and Velmurugan, V. "Artificial neural network modeling of a photovoltaicthermal evaporator of solar assisted heat pumps", Energy, 93, Part 1, pp. 908-922 (2015).

30. Salimiasl, A. and Özdemir, A. "Analyzing the performance of artificial neural network (ANN)-, fuzzy logic (FL)-, and least square (LS)-based models for online tool condition monitoring", The International Journal of Advanced Manufacturing Technology, pp. 114 (2016).

\section{Biographies}

Aydin Salimiasl received his $\mathrm{PhD}$ in Mechanical Engineering from University of Gazi, Ankara, Turkey in 2014. He is currently an Assistant Professor at the Department of Mechanical Engineering, Payame Noor University, Iran.

Ayhan Erdem received his $\mathrm{PhD}$ in Computer Engineering from University of Gazi, in 2001. He is currently a Professor at the Department of Computer Engineering, University of Gazi, Ankara, Turkey.

Mohammad Rafighi received his master's degree in Mechanical Engineering from University of Gazi in 2014. He is currently $\mathrm{PhD}$ student in Mechanical Engineering, University of Gazi, Ankara, Turkey. 